\title{
Wnt signaling pathways meet Rho GTPases
}

\author{
Karni Schlessinger, ${ }^{1,3}$ Alan Hall, ${ }^{1}$ and Nicholas Tolwinski ${ }^{2}$ \\ ${ }^{1}$ Cell Biology, Memorial Sloan-Kettering Cancer Center, New York, New York 10065, USA; ${ }^{2}$ Developmental Biology, Memorial \\ Sloan-Kettering Cancer Center, New York, New York 10065, USA
}

Wnt ligands and their receptors orchestrate many essential cellular and physiological processes. During development they control differentiation, proliferation, migration, and patterning, while in the adult, they regulate tissue homeostasis, primarily through their effects on stem cell proliferation and differentiation. Underpinning these diverse biological activities is a complex set of intracellular signaling pathways that are still poorly understood. Rho GTPases have emerged as key mediators of Wnt signals, most notably in the noncanonical pathways that involve polarized cell shape changes and migrations, but also more recently in the canonical pathway leading to $\beta$-catenin-dependent transcription. It appears that Rho GTPases integrate Wnt-induced signals spatially and temporally to promote morphological and transcriptional changes affecting cell behavior.

The canonical Wnt signaling pathway controls the stability of $\beta$-catenin. Under basal conditions, a "destruction complex" consisting of two ser/thr kinases, GSK-3 and CKI, and two scaffold proteins, Axin and APC, promotes degradation of $\beta$-catenin. Wnt ligands lead to inactivation of this destruction complex, allowing $\beta$-catenin to accumulate, translocate to the nucleus, and, together with its partner TCF/LEF, activate a transcriptional program (Grigoryan et al. 2008; Huang and He 2008). Mutations in components of this pathway (e.g., loss of APC) that allow $\beta$-catenin to accumulate in the absence of ligand are frequently found in human cancers (Polakis 2007).

Much less well understood are noncanonical Wnt signaling pathways, which can be characterized best as being TCF $/ \beta$-catenin transcription-independent. The planar cell polarity (PCP) pathway, for example, promotes polarization within the plane of a tissue, such that cells organize themselves in a particular orientation with respect to a common body axis. This involves the asymmetric segregation of proteins within each cell and allows processes such as hair growth or cell division to occur in a spatially coordinated way throughout the

[Keywords: Wnt; Rho GTPases; canonical Wnt signaling; noncanonical Wnt signaling; polarity; planar cell polarity]

${ }^{3}$ Corresponding authors.

E-MAIL schlessk@mskcc.org; FAX (212) 717-3604.

Article is online at http://www.genesdev.org/cgi/doi/10.1101/gad.1760809. tissue (Strutt 2002; Klein and Mlodzik 2005; Barrow 2006; Seifert and Mlodzik 2007; Green et al. 2008a). Convergent extension (CE) movements, often a major feature of tissues undergoing extensive morphogenesis such as vertebrate gastrulation, also involve Wnt signaling components acting in a noncanonical context (Seifert and Mlodzik 2007).

The first Wnt ligand was discovered more than two decades ago, and 19 distinct family members are now known to be encoded in the human genome (see the Wnt homepage http://www.stanford.edu/ rnusse/wntwindow. html; Rijsewijk et al. 1987). Specific Wnt ligands (Wnt-4, Wnt-5a, and Wnt-11) appear to activate noncanonical, rather than canonical, pathways, although it has been argued that receptor expression patterns may, in fact, be more relevant than the ligand in the choice of downstream signaling (Logan and Nusse 2004). In addition to the 10 mammalian Frizzled $(\mathrm{Fz})$ receptors and their LRP5/6 coreceptors, the ROR and Ryk families of transmembrane receptors interact with Wnt ligands, allowing for significant complexity in the initiation of signaling (Green et al. $2008 b)$. Downstream from receptors, Dishevelled, a key regulator of $\beta$-catenin stability during canonical signaling, also mediates noncanonical pathways, but how it accomplishes this dual role is unclear.

Important insights into PCP signaling first emerged from genetic studies in Drosophila, which uncovered a number of proteins specific to PCP, but also Rho GTPases, which have a broad range of activities affecting many other aspects of cell behavior. Rho family proteins are molecular switches that cycle between an active (GTP-bound) and an inactive (GDP-bound) conformation and are under the control of guanine nucleotide exchange factors (GEFs) and GTPase-activating proteins (GAPs). The three best-studied members of this family, Rho, Rac, and Cdc42, regulate the assembly and organization of the actin cytoskeleton in all eukaryotic cells. Rho controls the assembly of actin:myosin filaments to generate contractile forces, while Rac and $\mathrm{Cdc} 42$ promote actin polymerization at the cell periphery to generate protrusive forces, in the form of lamellipodia and filopodia, respectively (Jaffe and Hall 2005). Rho GTPases are therefore ideally placed to mediate a key feature of noncanonical signaling; namely, the polarized reorganization of the actin cytoskeleton leading to changes in cell shape 
and cell movement. More unexpectedly, new experimental work has uncovered a role for Rho GTPases in canonical signaling, though this appears to be independent of actin cytoskeletal changes. Our aim here is to review the evidence and implications for this convergence of the Wnt and Rho GTPase signaling systems.

\section{Genetic evidence for Rho GTPase involvement in noncanonical Wnt signaling}

One of the best-studied systems for studying PCP signaling is the organization of the Drosophila wing and eye (Strutt 2002; Klein and Mlodzik 2005). In the wing, PCP is manifest by the organization of cells within the tissue along the proximal-distal axis, such that each cell produces a single, actin-rich hair pointing distally (Fig. 1A). In the eye, PCP is evident in the regular arrangement of ommatidia with respect to the dorso-ventral and anteriorposterior axes. Although the final output is different in these two developmental processes (in the former case consisting of cell organization and actin hair polarity, and in the latter case, cell-type specification plus mophogenetic movements), a similar set of signaling components is required, which includes Frizzled, Dishevelled, and a set of PCP-specific genes (Prickle, Strabismus, Flamingo, and Diego). The biochemical mechanism by which they act to establish PCP is not clear, though it appears to depend on their asymmetric localization at the cell periphery (Klein and Mlodzik 2005).
The first genetic evidence for the involvement of a Rho GTPase in PCP signaling came with the identification of a Rho hypomorphic mutation that caused patterning defects in the Drosophila wing and eye, reminiscent of those observed in Frizzled and Dishevelled mutants (Strutt et al. 1997). Further analysis revealed that attenuation of Rho activity efficiently suppressed the effects of Frizzled or Dishevelled overexpression, leading to the conclusion that Rho acts downstream from these two proteins in PCP signaling in the fly (Fig. 1A). Interestingly, it appears that Wnt ligands are not required in this pathway. A role for Rac in PCP first emerged through experiments in which a dominant-negative version of the protein was expressed in the fly eye (Fanto et al. 2000). These studies concluded that Rac and Rho likely mediate distinct pathways downstream from Dishevelled and that Rac signals to the nucleus through Msn, a STE20 kinase that activates JNK (a microtubule-associated protein [MAP] kinase) (Fig. 1A). Subsequent work has, however, raised concerns about these conclusions, since a combined direct loss of function of the three Rac isoforms, Rac1, Rac2, and Mtl, produced no defects in PCP (HakedaSuzuki et al. 2002). This suggested that the dominantnegative constructs used in the other work might have had off-target effects. More recently this issue has been readdressed and a mild PCP phenotype reported for the triple (Rac1, Rac2, and Mtl) loss-of-function flies, and furthermore, this mild phenotype could be augmented when combined with a hypomorphic Cdc42 mutation
Figure 1. Rho GTPases in noncanonical Wnt signaling. $(A)$ During PCP signaling in the Drosophila wing, activation of Frizzled in the distal part of each hair cell (green shading) promotes localized Rho activation, which is required for actin-rich hair formation. In parallel, activation of Rac by Frizzled/Dishevelled leads to activation of JNK/p38 MAP kinases, which in the fly eye at least leads to changes in gene expression. (A) Apical; (B) basal; (P) proximal; (D) distal. (B) During vertebrate convergent extension movements, cells elongate and intercalate at the midline. Activation of Frizzled promotes Rho, Rac, and Cdc 42 activation, required for several different outcomes: Rac and $\mathrm{Cdc} 42$ are required for polarized protrusive activity (shown in red) and cell elongation. They also activate JNK, though the role of this pathway is not known. Cdc42 modulates cellcell contacts (shown in blue) in a Dishevelledindependent mechanism, through activation of heterotrimeric G proteins and PKC signaling. And finally, Rho activation is required for actin:myosin contractility.

\section{A.}

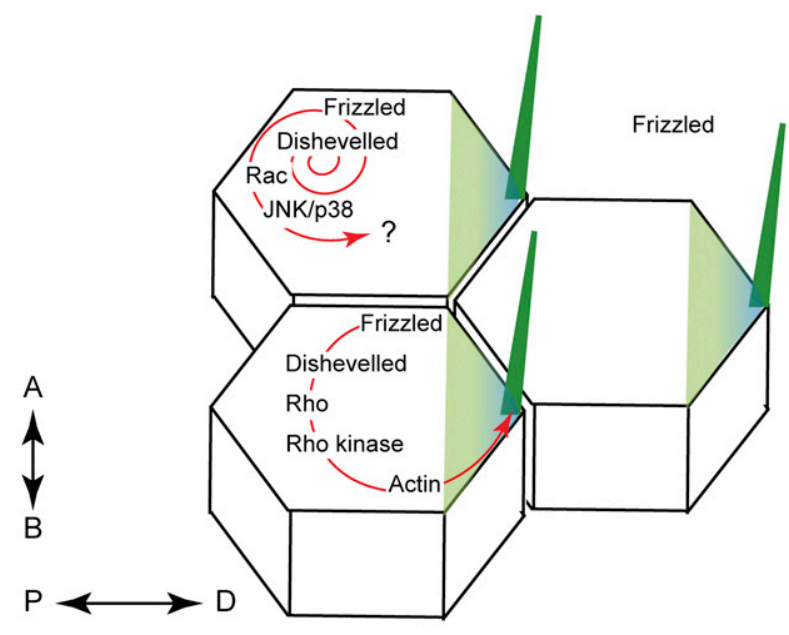

B.

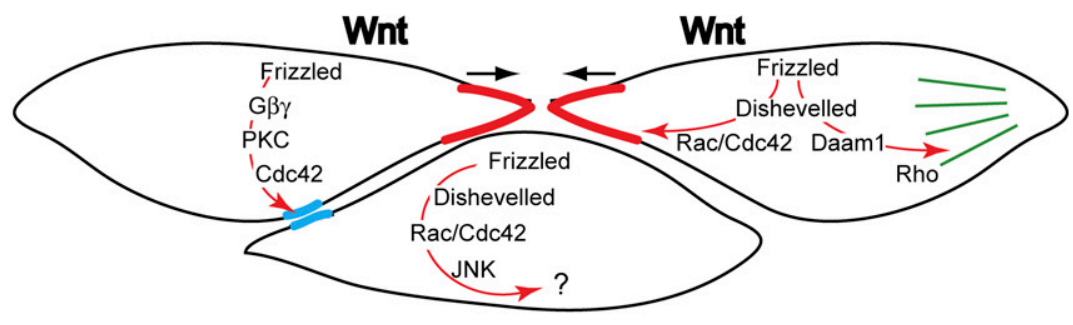


(Munoz-Descalzo et al. 2007). Since, dominant-negative Rac has been shown to inhibit both Rac and Cdc42 in some, though not all, circumstances, it appears that all these observations can be reconciled if Rac1, Rac2, Mtl, and Cdc42 share functional redundancy (at least in the context of these genetic manipulations). The original observation that JNK is downstream from Rac has been modified somewhat too, with the observation that $\mathrm{p} 38$, another MAP kinase activated by Msn, acts redundantly with JNK in the PCP pathway (Paricio et al. 1999).

Parallel studies using ectopic expression of Rho GTPase mutants have revealed additional contributions to wing development. A dominant-negative form of Drosophila Cdc42 expressed in the wing resulted in the failure of cells to elongate in the apical-basal direction, in part because of misorganization of the actin cytoskeleton (Eaton et al. 1995). Cdc42 was also required for proper wing hair formation, specifically for actin polymerization in the wing hair (Eaton et al. 1996). Expression of dominant-negative Rac, on the other hand, led to defects in actin assembly at adherens junctions, as well as the growth of ectopic wing hairs, caused in part at least by disorganization of the microtubules at the apical surface of wing cells (Eaton et al. 1995, 1996). It appears that in these experiments the two dominant-negative constructs showed at least some specificity, since the phenotypes were not identical. These experiments further emphasize the difficulty in interpreting inactivation studies with Rho family GTPases, since each acts as a regulator of multiple biochemical pathways: F-actin assembly, microtubule organization, MAP kinase cascades, and cell-cell and cell-matrix adhesions, to name just a few (Jaffe and Hall 2005).

In summary, all the data point to a central role for Rho GTPases in PCP and other aspects of cytoskeletal organization associated with Drosophila wing and eye development (Munoz-Descalzo et al. 2007). The Rho protein acting downstream from Frizzled/Dishevelled regulates cytoskeletal reorganization through dRok (Drosophila Rho kinase) and myosin II, as well as nuclear responses through an unknown mechanism (Winter et al. 2001). Rac family proteins participate in a distinct pathway downstream from Frizzled/Dishevelled, which mediates nuclear responses through the JNK/p38 MAP kinase cascades and the Fos and Jun transcription factors (Weber et al. 2008), though they likely promote cytoskeletal changes as well. There are clearly still many missing pieces to these pathways; for example, the nature of the nuclear effects and the identity, spatial localization, and relationship to core PCP proteins of the GTPase activators.

\section{Biochemical evidence for Rho GTPases in noncanonical Wnt signaling}

Xenopus laevis

Although not genetically tractable, Xenopus has provided much insight into the mechanisms of Wnt signaling in development. During gastrulation, mesodermal tissues converge medio-laterally and extend anterior-posteriorly, thus elongating the body axis (Fig. 1B; Keller 2002). The driving force for $\mathrm{CE}$ comes from polarized cell protrusions and migration in the dorsal marginal zone (DMZ) of the embryo, driven by organized cytoskeletal changes. CE shows many aspects of PCP, and indeed, some of the core PCP components identified in Drosophila (e.g., Strabismus) as well as noncanonical Wnt pathways are involved (Wallingford et al. 2000; Goto and Keller 2002). Unlike Drosophila PCP pathways, where the ligand and receptor have not yet been identified conclusively, the major ligand regulating convergent extension in Xenopus is believed to be Wnt-11, and its receptor is Fz7 (Djiane et al. 2000; Penzo-Mendez et al. 2003; Tanegashima et al. 2008).

There is compelling evidence that Rho and Rac cooperate with Wnt/Fz to promote important aspects of CE. Pull-down assays (to detect levels of active, GTP-bound GTPases) have uncovered activation of endogenous Rho and Rac (but not Cdc42) in areas undergoing convergent extension (i.e., the DMZ) (Habas et al. 2001). Rho activation was blocked after expression of a dominant-negative Wnt-11, an extracellular fragment of Fz7, or an inhibitor of Dishevelled. The identification of Daam1, a novel formin domain-containing protein that interacts with the PDZ domain of Dishevelled, has provided some further insight into how Fz7 talks to Rho (Habas et al. 2001, 2003). Daam1 acts downstream from Fz7, interacts with both the PDZ and DEP domains of Dishevelled, and is essential for Rho activation. This has led to speculation that it probably interacts with a Rho GEF, thus completing the link between ligand and GTPase (Fig. 1B). A later report from Habas et al. (2003) showed that Rac and JNK are activated downstream from Wnt-11 and Fz7 in the DMZ. This is Dishevelled-dependent /though only the DEP domain, and not the PDZ domain, is involved) and Rho/Daam1independent. Similar to PCP in Drosophila, it seems that Dishevelled is capable of independently regulating the activities of both Rho and Rac.

Little is known about the immediate upstream regulators of Rho and Rac-the GEFs and GAPs-during CE. However, a recent paper reports a significant step forward, with evidence that WGEF, a Rho-specific exchange factor, is required for CE (Tanegashima et al. 2008). Antisense morpholinos that deplete WGEF protein levels blocked animal cap explant elongation (as well as many other aspects of early development, including neural tube closure defects; see later section on chick models), and this was rescued by expression of activated Rho. Furthermore, expression of WGEF partially rescued impaired CE in embryos depleted of Wnt-11, but not in embryos expressing a dominant-negative Daam1. Finally, WGEF interacted with Dishevelled, but a WGEF with a small $\mathrm{N}$-terminal deletion did not, yet was constitutively activated as an exchange factor. It appears that Dishevelled binding relieves the effects of an autoinhibitory domain in WGEF, a mechanism of activation common to several other members of this large (82 in mammals) family of GEFs for Rho GTPases (Schmidt and Hall 2002). The downstream effects of Rho and Rac activities in the noncanonical pathways are likely to be numerous. Careful visualization of cell behavior during $\mathrm{CE}$ has demonstrated 
that both Rho and Rac are required for reorganization of the actin cytoskeleton that drives polarized cell shape changes and cell movement (Tahinci and Symes 2003). This involves lamellipodial- and filopodial-like activities at the cell periphery and actomyosin contractile forces, most likely involving Rho kinase, in the cell body (Fig. 1B; Marlow et al. 2002). However, Rho and Rac can influence cell-cell adhesions as well as JNK/p38 MAP kinasesactivities that are also important for CE processes.

Several experimental observations provide a strong case for Cdc42 playing a specific, nonredundant role in CE. Microinjection of mRNA encoding a dominantnegative version of $\mathrm{Cdc} 42$ into the animal pole region of four-cell stage embryos was able to rescue a defect in animal cap explant elongation induced by overexpression of Wnt-11 or Fz7 (Djiane et al. 2000). A later study by others showed that expressing either dominant-negative or wild-type Cdc42, in either animal pole or marginal zone regions of four-cell embryos, inhibited convergent extension movements (Choi and Han 2002). It seems clear, therefore, that Cdc42 plays an important role in CE and that this is not redundant with Rho or Rac. However, the mechanism of $\mathrm{Cdc} 42$ activation appears to be quite different from fly PCP pathways, or from Rho and Rac activation pathways described in CE. First, dominantnegative Cdc42 does not suppress the effects of Dishevelled overexpression (Choi and Han 2002). This has been taken to imply that Dishevelled is not required for Cdc42 activation, although the interpretation is not straightforward given the multiple effects of Dishevelled (in activating Rac and Rho, for example) on CE. Second, activation of Cdc42 by Wnt-11 is dependent on G $\beta \gamma$ (subunits of heterotrimeric $\mathrm{G}$ proteins) acting through a classical protein kinase $\mathrm{C}$ (PKC), which is again consistent with a Dishevelled-independent pathway (Choi and Han 2002; Penzo-Mendez et al. 2003). This signaling pathway upstream of Cdc42 is suggestive of Wnt/ $\mathrm{Ca}^{2+}$ signaling, another noncanonical pathway first described for Wnt-5a and Fz2 that regulates cadherin-based cell-cell adhesion (Kuhl et al. 2000). Consistent with this, dominant-negative $\mathrm{Cdc} 42$ was also able to rescue the impairment of cell-cell adhesion induced by overexpression of Wnt-5a (Choi and Han 2002). The dynamic regulation of cell-cell adhesion between intercalating cells is a crucial aspect of convergent extension processes, suggesting an important and specific contribution of Cdc42 in CE (Fig. 1B). The observations that Cdc42 can rescue Wnt-11- and Wnt-5a-induced phenotypes and that in each case this is through a Dishevelled-independent route involving heterotrimeric $\mathrm{G}$ proteins and $\mathrm{PKC}$, suggest that both Wnt ligands may influence cell-cell adhesions during CE through Cdc42.

\section{Zebrafish}

A role for Rho family GTPases downstream from Wnts has been demonstrated during a variety of morphogenetic processes associated with zebrafish development. The pathways involved in CE movements during gastrulation are very similar to those reported in Xenopus-Wnt-11/ Wnt-5; Dishevelled; and all three Rho GTPases, Rho, Rac, or Cdc42-are required, as are the core Drosophila PCP proteins, Prickle and Diversin (similar to Diego) (Marlow et al. 2002; Veeman et al. 2003; Matsui et al. 2005; Ulrich et al. 2005; Moeller et al. 2006; Matthews et al. 2008). Interestingly, Zhu et al. (2006) has reported that expression of Rho rescues not only Wnt-11 mutants but also Wnt-5 mutants, suggesting that in CE these two ligands activate similar if not identical, noncanonical signaling pathways. The same group found that coexpression of Rho kinase and $\mathrm{mDia}$, two Rho target proteins, rescued Rho or Wnt-11 mutants. This striking result suggests that these are the most important targets downstream from Rho in this noncanonical pathway. On reflection, however, this is a surprising result, since it implies that Rac is not required in the Wnt-11 pathway. Results reported by Moeller et al. (2006) are more consistent with a role for both Rho and Rac, in that coexpression of both were required to rescue the effects induced by inhibition of Dishevelled. This same group provided evidence that Diversin, a core PCP protein similar to Drosophila Diego, interacts directly with the DEP domain of Dishevelled and is required for Rho activation-a similar story to that reported for the unrelated Damm1 protein in the Xenopus system (Habas et al. 2001; Moeller et al. 2006).

Zebrafish analysis has led to the identification of other morphogenetic processes, occurring later in development, that use noncanonical Wnt pathways. The migration of endodermal precursors of the heart from bilateral positions to the midline is impaired after expression of the Dishevelled DEP domain or dominant-negative Rho (Matsui et al. 2005). Inhibition of JNK, PKC, Rac, or Cdc42, on the other hand, had no significant effect, suggesting that other components required for CE are not involved in this migration process. Rho GTPases are known to play important roles in driving cell migration (they can arguably be regarded as part of the core migration machinery), and so there could be other interpretations to these results. However, expression of a constitutively activated Rho was able to rescue, at least partially, the inhibition of migration caused by Dishevelled DEP expression, thus providing quite reasonable evidence that Rho is playing a specific role downstream from Wnt/Dishevelled. Nevertheless, activated Rho did not rescue the CE defects induced by Dishevelled DEP, and perhaps its role in the two processes might not be the same-the migration of endodermal precursors being perhaps more like a typical chemotactic response. Some similar observations have been made with neural crest cells, where inhibition of Dishevelled, Wnt-11/5, or Strabismus all lead to problems with the directionality of cell migration, though in this case, Matthews et al. (2008) proposed that a major role of Rho downstream from Dishevelled is to locally inhibit Rac.

\section{Chick}

Noncanonical pathways control cell movements during chick development, though the contribution of Rho GTPases has not been extensively explored. Recently however, Rho was identified as a major player in the formation of the neural tube from the neural plate, 
a process requiring organized morphogenetic cell movements (Kinoshita et al. 2008). This in itself is not so surprising, the Rho-dependent and spatially localized activation of actin:myosin contractility being a major driving force of shape changes. However, Kinoshita et al. (2008) found that Wnt-11, Fz7, and Dishevelled are also required for tube formation and, most importantly, for the accumulation of Rho at the apical surface of neural plate cells. The result is intriguing, but the interpretation is not straightforward; localized activation of Rho leading to morphogenetic shape changes are important during gastrulation in Drosophila, but this is mediated by polarized secretion of a protein ligand (Fog) acting through a G-protein-coupled receptor, and not by Wnt/ PCP pathways (Kolsch et al. 2007).

\section{Mammalian cells}

Attempts have been made to facilitate the mechanistic analysis of the noncanonical Wnt pathway and the contribution of Rho GTPases, by reconstructing these signaling pathways in mammalian cell lines. Thus, overexpression of Dishevelled activated JNK in NIH 3T3 cells and this was Cdc42/Rac-dependent, while expression of $\mathrm{Fz} 7$ or Fz1, but not Fz5 or Fz2, in 293T cells induced both Rho and Rac (not Cdc42) activation (Moriguchi et al. 1999; Habas et al. 2001, 2003). However, Wnt-11 did not activate Rho in the same cells, whereas Wnt-1, which is thought to activate only canonical pathways, activated Rho and Rac (again not Cdc42). It seems highly likely that the cell type-specific expression patterns of Frizzled receptors and Rho GTPases regulators (GEFs and GAPs) play a major role in determining the outcome of these types of experiment. Cell lines should, therefore, be useful in identifying some of the general mechanistic features of PCP/CE signaling, but not the specific components relevant to a particular in vivo process.

\section{Rho GTPases and canonical Wnt signaling}

Despite extensive analysis of canonical Wnt signaling over many years, only recently has a role for Rho GTPases been identified. There are clearly many missing links in the canonical pathway, as it is currently known, and one of these is the mechanism by which cytoplasmic $\beta$ catenin is imported into and exported from the nucleus (Henderson and Fagotto 2002). It appears that Rac might play a role in this. Using a colon cancer cell line in which the canonical Wnt pathway is constitutively activated, it was reported that $\beta$-catenin/TCF transcription was inhibited by dominant-negative Rac and potentiated by constitutively activated Rac. Esufali and Bapat (2004) proposed that Rac enhances nuclear $\beta$-catenin accumulation and that this might be facilitated by a nuclear import-like sequence found close to the $\mathrm{C}$ terminus of one of the three mammalian Rac isoforms, Rac1. This idea was further strengthened with an observation in Drosophila embryos, where an inactivating mutation in RacGAP50C promoted canonical Wnt signaling (Jones and Bejsovec 2005). RacGAP50C, which was identified previously as an essential player in cytokinesis, is a neg- ative regulator of Rac. Jones and Bejsovec (2005) speculated that this might imply a role for the cytoskeleton in canonical signaling. The most recent paper to address this issue reports that Rac-mediated activation of JNK leads to phosphorylation of $\beta$-catenin on two specific sites promoting nuclear localization (Wu et al. 2008). Although much of this latest study was done with tissue culture cells, they provided confirmatory in vivo data showing that ablation of Racl in the mouse embryonic limb bud ectoderm phenocopies loss of $\beta$-catenin. A further study showed that Tiam1, a Rac GEF, can be coprecipitated with $\beta$-catenin and GTP-bound Rac-an interaction that was promoted by Wnt3a (Buongiorno et al. 2008). In a final twist to the story, DOCK4, another Rac-specific GEF, has been shown to be a part of the $\beta$-catenin degradation complex, but whether this is related to the proposed role of Rac in nuclear translocation is not known (Upadhyay et al. 2008). This is certainly an unexpected role for a Rho family GTPase, and although the favored hypothesis seems to be a role in $\beta$-catenin nuclear import (Fig. 2), alternative hypotheses such as

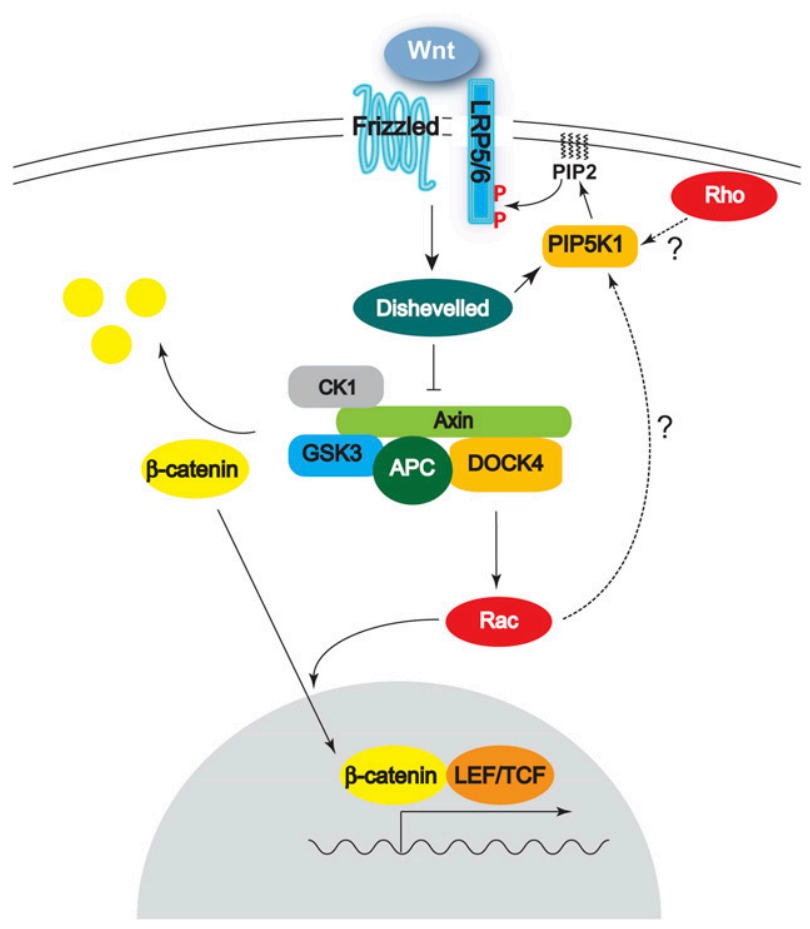

Figure 2. Rho GTPase signaling in the canonical Wnt pathway Rac participates in canonical Wnt signaling by promoting nuclear accumulation of $\beta$-catenin. RacGAP50C- and Racmediated phosphorylation of $\beta$-catenin by JNK are also required (see the text). A guanine nucleotide exchange factor, DOCK4, is found associated with the destruction complex, though it has not been directly implicated in nuclear import. PIP2-dependent phosphorylation of LRP5/6 is important for receptor aggregation and enhanced Wnt signaling downstream from Dishevelled. Both Rac and Rho have been implicated in regulating the enzyme PIP5K1, responsible for PIP2 biosynthesis, though whether they do so during canonical Wnt signaling is not known. 
promoting tighter binding to DNA complexes or impaired export could be involved. Finally, it is interesting to note that a similar role for Rac and MgcRacGAP (the mammalian ortholog of RacGAP50C) has been proposed for the nuclear import of another transcriptional regulator, STAT, involved in cytokine signaling (Kawashima et al. 2006).

New insights into the proximal events of canonical Wnt signaling have raised another potential link to Rho GTPases. It is known that canonical Wnt signaling requires phosphorylation of the LRP5/6 coreceptors and a recent paper shows that localized synthesis of the phosphoinositide lipid $\mathrm{PIP}_{2}$ is involved (Fig. 2; Pan et al. 2008). Synthesis of $\mathrm{PIP}_{2}$ requires the consecutive activities of two lipid kinases, phosphatidylinositol 4-kinase (PI4K) and phosphatidylinositol 4-phosphate 5-kinase (PIP5K), and it turns out that both of these enzymes are required for canonical Wnt signaling in Xenopus embryos. Not only does addition of Wnt stimulate $\mathrm{PIP}_{2}$ production, but PIP5K also interacts with Dishevelled. The potential interest from a GTPase point of view is that Rac and Rho can promote membrane translocation and activation of PI4K and PIP5K kinases, though it remains to be seen whether they play any role in this localized phosphorylation of LRP5/6 by canonical Wnts (Wei et al. 2002; Weernink et al. 2004; Yang et al. 2004).

\section{Emerging examples of Wnt and Rho GTPase interactions}

\section{Mitotic spindle polarity}

Wnt signaling and Rho GTPases can each influence the position and orientation of the mitotic spindle during cell division, although it is not yet clear whether they contribute to the same or parallel pathways. In Caenorhabditis elegans, the Frizzled receptor MOM-5 is required for the asymmetric division of neuroblasts (Hawkins et al. 2005; Hardin and King 2008). Dishevelled localizes to the cell cortex asymmetrically in a MOM-5-dependent manner, while depletion of either leads to the generation of two anterior-like neuroblasts from the precursor, instead of one anterior and one posterior cell. It is assumed that this represents a noncanonical Wnt pathway talking to mitotic spindle microtubules, although cortical actin may also be involved. Similarly, the Wnt LIN-44 and the Frizzled receptor LIN-17 are required for the asymmetric division of the male-specific blast cell (Wu and Herman 2006). GSK-3 and axin, components of the canonical pathway, are not required, but the PDZ and DEP domains of Dishevelled (MIG-5 in worms), Rho, and Rho kinase are, again suggesting a noncanonical, PCP-like pathway is involved in spindle orientation.

Rho and Cdc42, together with the Par proteins, play key roles in positioning the spindle asymmetrically during the first cell division of the C. elegans embryo, while at the two-cell stage, $\mathrm{Cdc} 42$ is required for spindle reorientation (rotation) to occur specifically in the P1 and not the $\mathrm{AB}$ daughter cell (Fig. 3; Gotta et al. 2001; Cowan and Hyman 2007). At the four-cell stage, however, a Wnt signal derived from the P2 cell drives spindle reorientation in the neighboring endoderm precursor cell (EMS) to align along the AP axis. The Wnt signaling pathways involved here are complex. A canonical Wnt pathway controls endoderm induction, through the Frizzled receptor MOM-5, but a noncanonical pathway, also dependent on MOM-5, is required for spindle reorientation (Schlesinger et al. 1999). This is not a "typical" noncanonical pathway-it is transcription-independent and Dishevelled does localize asymmetrically at the posterior of EMS; however, it involves GSK-3 and casein kinase I, components normally associated with the canonical pathway (Walston et al. 2004). It is not known whether Rho GTPases cooperate with Wnt in positioning the spindle in the EMS cell. Interestingly, this is reminiscent of a pathway identified in polarized migrating tissue culture cells, which also regulates the orientation of microtubules, though during interphase, not mitosis (Etienne-Manneville and Hall 2001, 2003; Schlessinger et al. 2007; see below).

Work in zebrafish has indicated that a PCP-like pathway regulates the orientation of cell division during vertebrate gastrulation (Gong et al. 2004). Mitotic divisions
Figure 3. Potential cooperation between Rho GTPases and Wnt signaling during asymmetric cell divisions in the C. elegans embryo. During the first two cell divisions, Par-3, Par-6, and aPKC localize asymmetrically in the C. elegans embryo (Par-6 in green). This localization is controlled (in part) by Cdc42 and is required for spindle positioning and asymmetric cell divisions (spindle shown in red). Depletion of Cde42 (Cde42 RNAi) results in delocalized Par-6 and allows both spindles to rotate. At the four-cell stage (but not before), Wnt signaling is required for an asymmetric cell division: A Wnt signal derived from the P2 cell orients the spindle of the neighboring EMS cell. Dishevelled (shown in blue) accumulates in the cortex at the EMS/P2 border. Loss of the Frizzled receptor MOM-5, or Dishevelled in the EMS cell prevents spindle reorientation. A possible role for Cdc42 during EMS spindle orientation has not been directly addressed. (A) Anterior; (P) posterior.

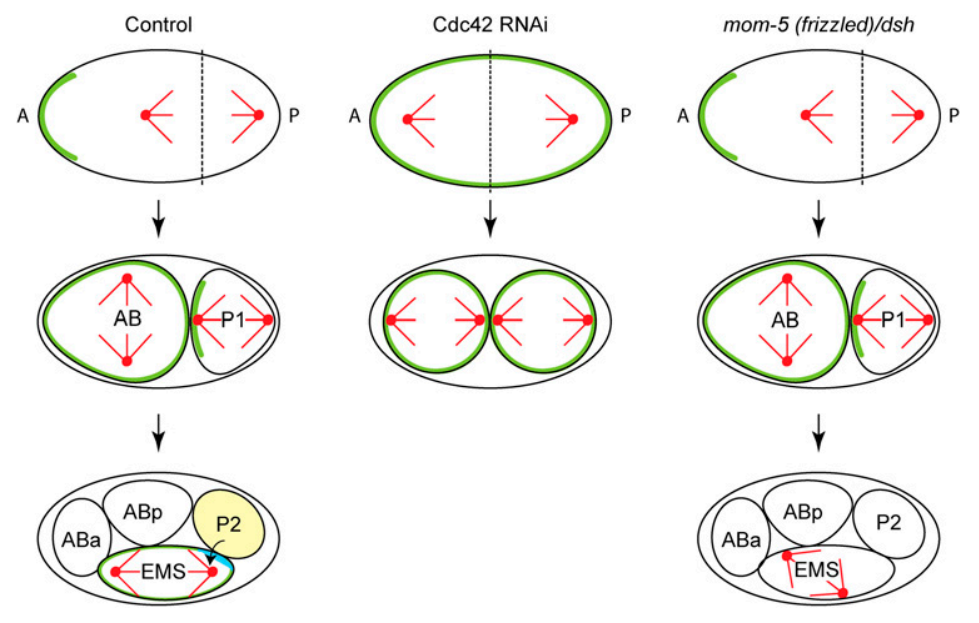




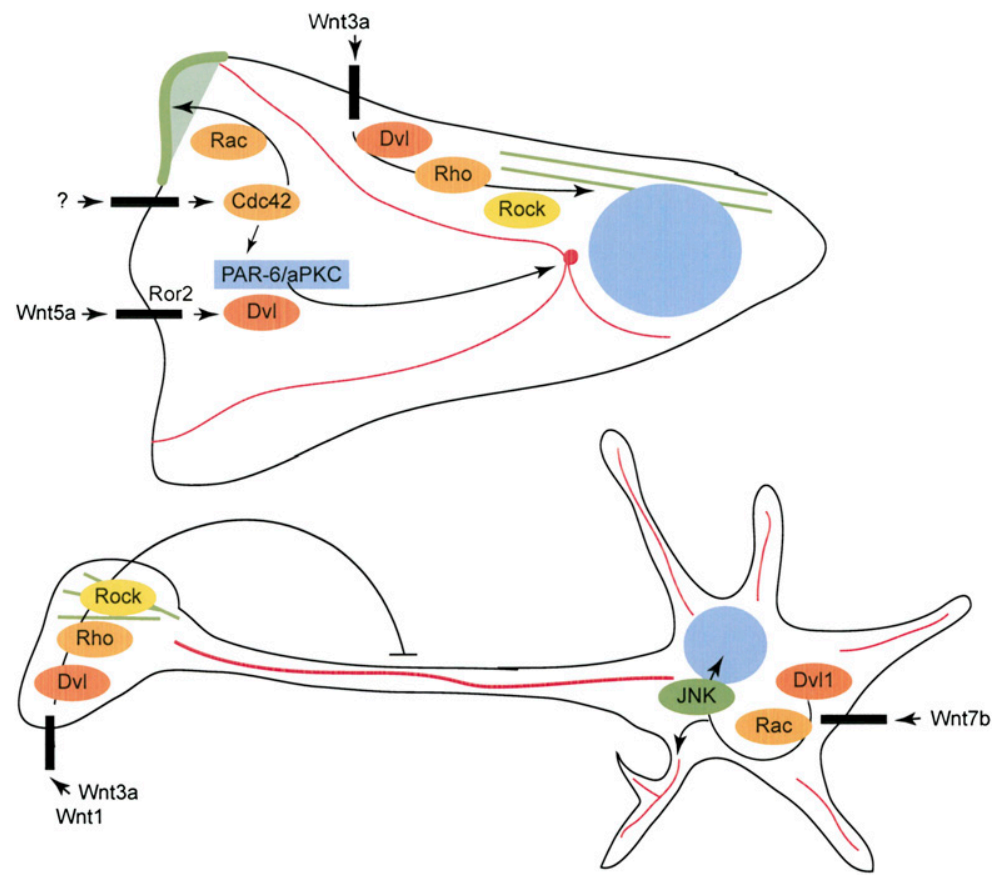

Figure 4. Cooperation between Rho GTPases and Wnt signaling during cell polarization. $(A)$ After scratching a monolayer of primary rodent fibroblasts, Cdc42 is activated at the leading edge. This promotes activation and recruitment to the leading edge of the Par6/aPKC complex. Wnt5a/Ror2 activation leads to the formation of a Dishevelled/aPKC complex, which is required for centrosome reorientation (red spot) and microtubule polarization (red lines). Since Wnt-5a secretion is not polarized, it is the activation of $\mathrm{Cdc} 42$ that provides the instructive polarity signal. Cdc42 activation is also required to localize Rac activity to the leading edge to promote actin-driven protrusions (shown as green shading). Wnt3a activates Rho/ROCK through Dishevelled, which could facilitate cell migration through the regulation of actin:myosin contractility (green lines). (B) In neurons, Wnts act both on the axon and dendrites to regulate neuronal morphogenesis. Wnt-5a together with Dishevelled and the Par-6/aPKC polarity complex are required for axon formation (see text). In addition, Wnt-1 and Wnt-3a have been reported to inhibit axon formation through the action of Dishevelled/Rho/ ROCK, while Wnt-7b promotes dendritic branching, through Rac/JNK, which affects gene expression as well as microtubule stability. in the epiblast occur with mitotic spindles oriented at a specific angle with respect to the animal-vegetal axis. This orientation is dependent on Wnt-11 and was randomized in the presence of a Dishevelled antagonist or after depletion of the core PCP protein Strabismus. Interestingly, additional defects in embryo extension were observed, suggesting an intimate link between oriented cell division and embryo morphogenesis and that PCP signaling may coordinately control both processes (Gong et al. 2004). Whether Rho GTPases play a role here is not yet known.

\section{Cell migration}

The contribution of Rho GTPases to cell migration has been studied extensively and in many different contexts, both in tissue culture as well as in vivo. A simple in vitro scratch assay (in a confluent monolayer), used by many groups to initiate and analyze cell migration, leads to polarization of the actin and microtubule cytoskeletons in leading edge cells (Nobes and Hall 1999). In this context, Cdc42 controls (1) the polarized location of Rac-mediated actin polymerization at the front of these cells and (2) the polarized reorientation of the microtubule cytoskeleton (often visualized as reorientation of the centrosome to face the direction of migration) (Fig. 4A). An asymmetrically localized, Cdc42-mediated signal transduction pathway responsible for microtubule reorganization has been identified that involves the Par6/ aPKC complex and several components of the canonical Wnt signaling pathway, specifically GSK-3 and the adenomatous polyposis coli tumor suppressor protein, APC (Etienne-Manneville and Hall 2003; Etienne-Manneville et al. 2005). There is no evidence, however, that canonical Wnt signaling plays any role in this process (it is transcription-independent); however, Dishevelled and the noncanonical ligand Wnt-5a are required (Schlessinger et al. 2007). Exactly how this noncanonical pathway interfaces with the Cdc42 pathway is not clear, although the Par6/aPKC complex, which is a direct target of Cdc42, can be coprecipitated with Dishevelled during polarization of rat embryo fibroblasts in a scratch

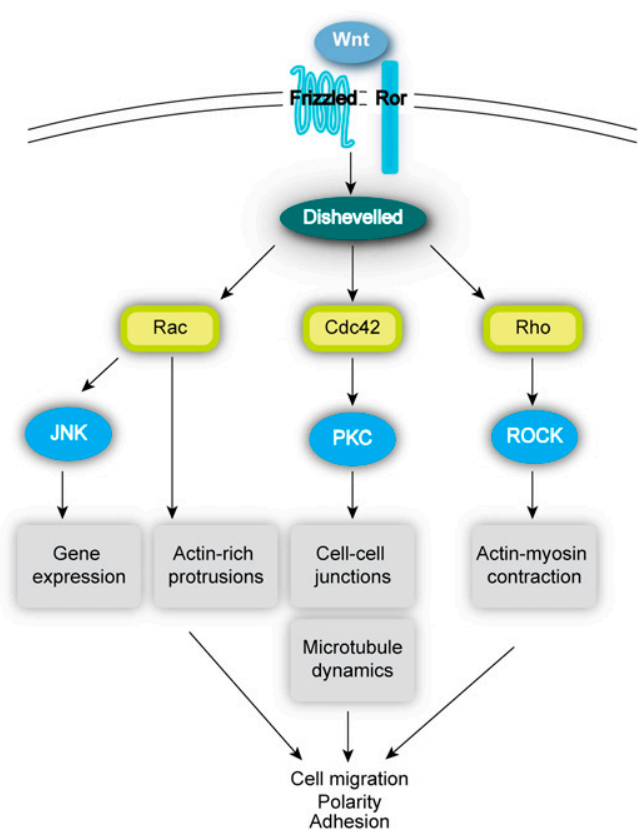

Figure 5. A proposed Wnt/GTPase pathway. Wnt ligands acting through different receptors cooperate with Rho GTPases to control diverse cellular responses. See the text for details. 
Schlessinger et al.

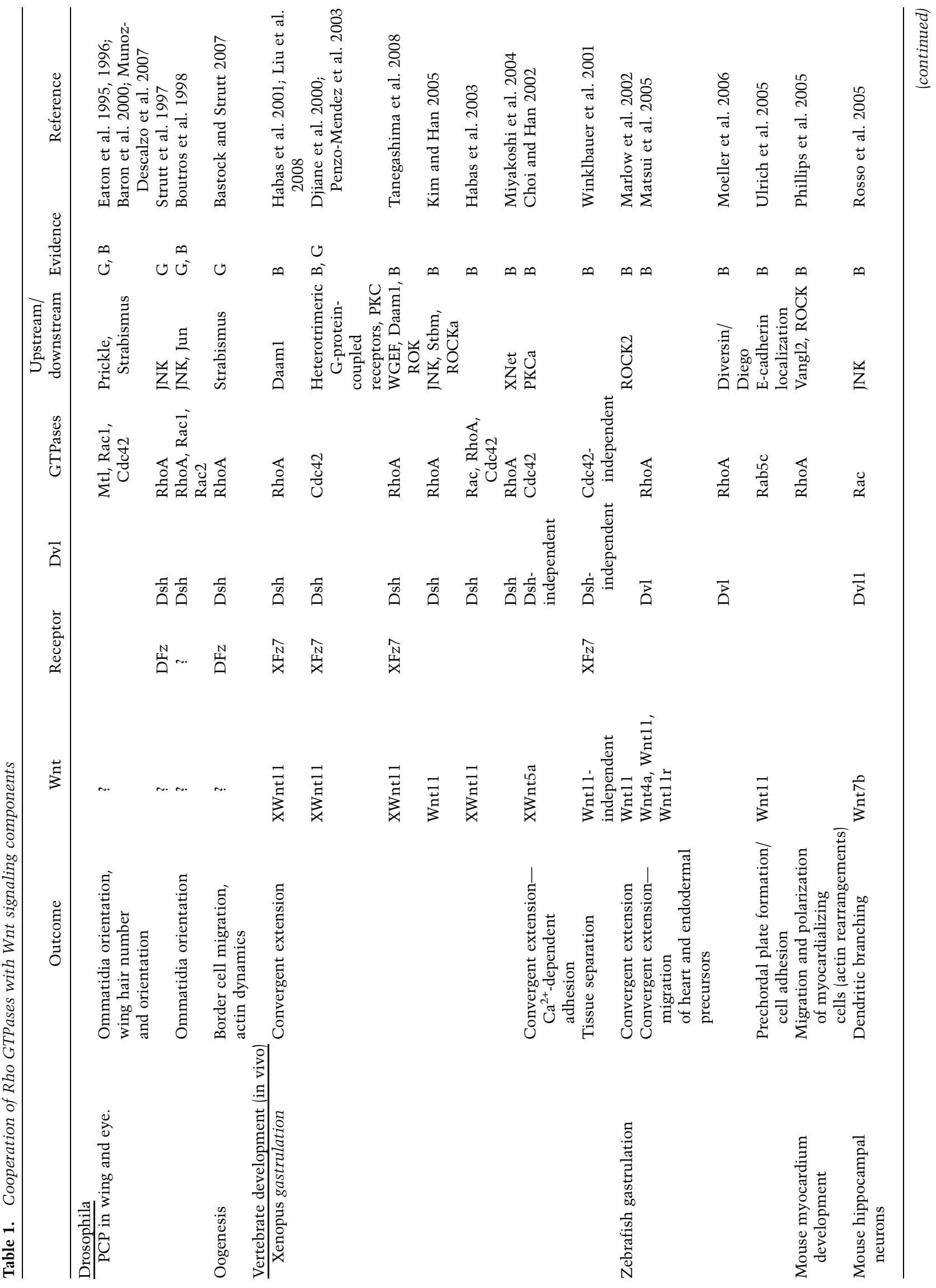




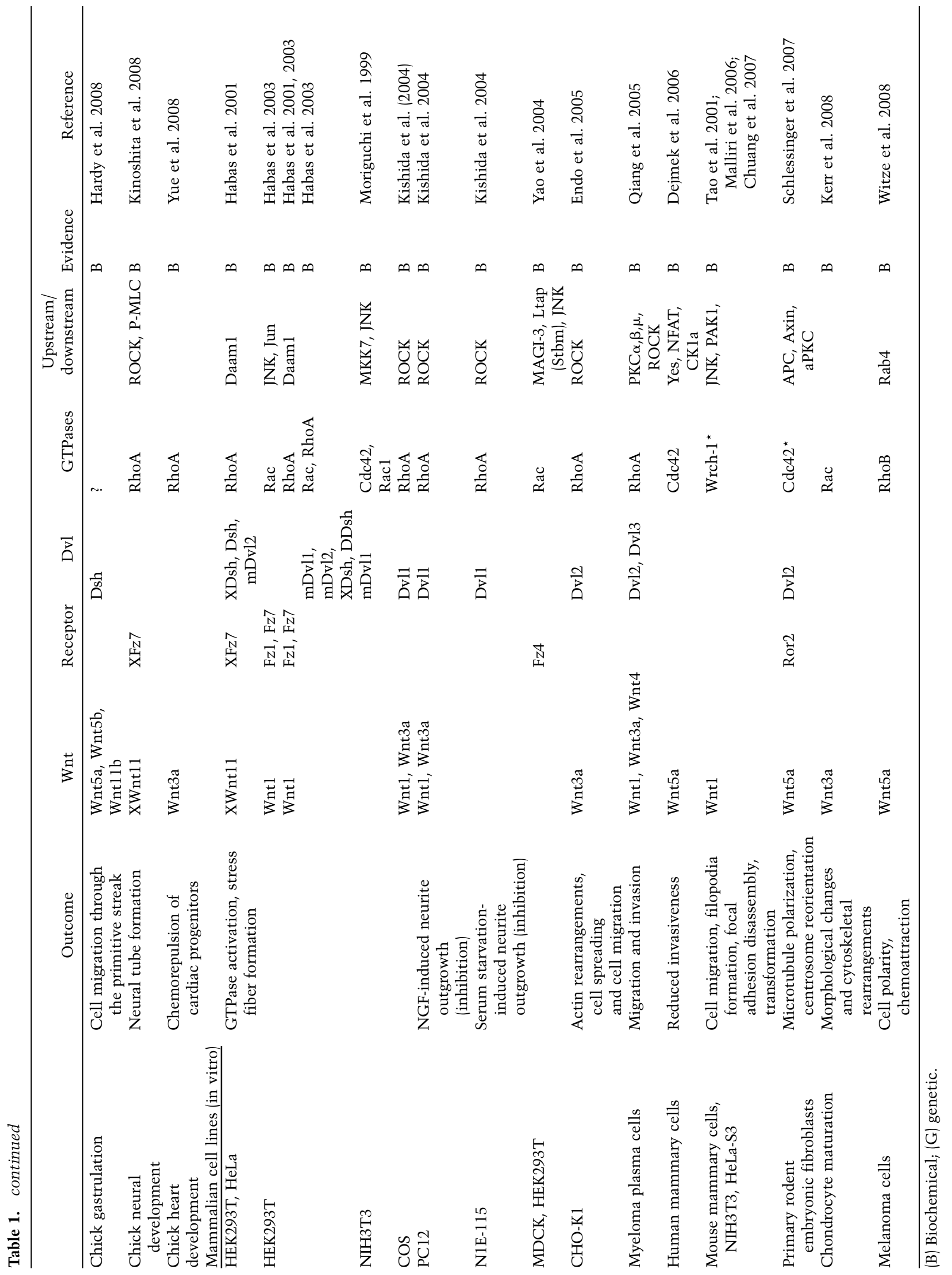


assay, as well as in hippocampal neurons (see below) during axon formation (Schlessinger et al. 2007; Zhang et al. 2007). Wnts have been shown to affect cell migration in other tissue culture assays, probably through noncanonical-like pathways, although these are not well characterized. Wnt-3a, for example, promotes the migration of $\mathrm{CHO}$ cells in a Dishevelled- and Rho-dependent manner, while Wnt-5a-stimulated migration of rodent embryo fibroblasts requires the Ror-2 coreceptor, again implying a noncanonical signal (Endo et al. 2005; Nishita et al. 2006; Schlessinger et al. 2007).

\section{Neuronal morphogenesis}

Many investigators have explored the mechanisms by which polarity is established in cultured neurons. After plating, hippocampal neurons develop several small, but highly dynamic neurite extensions, and a day or so later, one of these makes the decision to elongate and take on the characteristics of an axon. The mechanism of axon formation shows surprising similarities to microtubule polarization during directed cell migration as described above and involves Cdc42 and the Par6/aPKC complex acting through GSK-3 and APC (Shi et al. 2003, 2004; Schwamborn and Puschel 2004). More recently, yet more striking similarities with directed migration have been reported with the discovery that Wnt-5a and Dishevelled are also required for axon formation (Zhang et al. 2007). After axon formation, remaining neurites adopt dendritic like characteristics, and Wnt-7b has been reported to promote dendritic branching, through Dishevelleddependent activation of Rac and JNK (Fig. 4B; Rosso et al. 2005). It appears that at least one role of JNK is to regulate microtubule dynamics through phosphorylation of MAPs (Chang et al. 2003). Wnt-3a has been reported to affect growth cone morphology, again through effects on microtubule dynamics, while in differentiated PC12 cells, Wnt-3a promoted neurite retraction through a Dishevelleddependent activation of Rho and Rho kinase (Kishida et al. 2004; Purro et al. 2008).

\section{Conclusions}

The identification of Rac as an important component of canonical Wnt signaling came as a real surprise. Although it is probably too early to say how general a requirement this is, the Drosophila work, showing the importance of a Rac GAP in the canonical pathway, does provide strong in vivo support for this idea. Noncanonical signaling is still quite enigmatic, but the evidence that Rho GTPases play important roles in these pathways is strong and summarized in Figure 5. The analysis of PCP pathways in flies is relatively clear and shows the importance of Rho and Rac-like GTPases in controlling the actin cytoskeleton and nuclear responses downstream from Frizzled and Dishevelled. CE pathways analyzed in various vertebrates reveal significant biological and molecular similarities to PCP, with a clear role for Rho, Rac, and Cdc42 downstream from Frizzled, Dishevelled, and (unlike flies) Wnt ligands. The noncanonical Wnt/Fz/Dishevelled and Wnt/ $\mathrm{Ca}^{2+}$ pathways appear to be distinct and may, perhaps, reflect roads to $\mathrm{Rho} / \mathrm{Rac}$ and $\mathrm{Cdc} 42$, respectively.
Finally, the analysis of mitotic spindle orientation/ asymmetry, directed cell migrations, and neuronal morphogenesis points to an overlap between canonical and noncanonical components downstream from Frizzled/ Dishevelled in the control of microtubule polarity. These pathways also clearly interface with other polarity pathways, notably the Par proteins that have been linked, in turn, to Rho family members. Given the all-pervasive role of Wnts both in development and in adult regenerative processes (Table 1), it should come as no surprise that the signaling pathways are complex and versatile and that they exploit equally complex and versatile effectors of biochemical responses, the Rho GTPases.

\section{References}

Baron, M., O'Leary, V., Evans, D., Hicks, M., and Hudson, K. 2000. Multiple roles of the Dcdc42 GTPase during wing development in Drosophila melanogaster. Mol. Gen. Genet. 264: 98-104.

Barrow, J.R. 2006. Wnt/PCP signaling: A veritable polar star in establishing patterns of polarity in embryonic tissues. Semin. Cell Dev. Biol. 17: 185-193.

Bastock, R. and Strutt, D. 2007. The planar polarity pathway promotes coordinated cell migration during Drosophila oogenesis. Development 134: 3055-3064.

Boutros, M., Paricio, N., Strutt, D.I., and Mlodzik, M. 1998. Dishevelled activates JNK and discriminates between JNK pathways in planar polarity and wingless signaling. Cell 94: 109-118.

Buongiorno, P., Pethe, V.V., Charames, G.S., Esufali, S., and Bapat, B. 2008. Racl GTPase and the Racl exchange factor Tiam1 associate with Wnt-responsive promoters to enhance $\beta$-catenin/TCF-dependent transcription in colorectal cancer cells. Mol. Cancer 7: 73. doi:10.1186/1476-4598-7-73.

Chang, L., Jones, Y., Ellisman, M.H., Goldstein, L.S., and Karin, M. 2003. JNK1 is required for maintenance of neuronal microtubules and controls phosphorylation of microtubuleassociated proteins. Dev. Cell 4: 521-533.

Choi, S.C. and Han, J.K. 2002. Xenopus Cdc42 regulates convergent extension movements during gastrulation through Wnt/Ca ${ }^{2+}$ signaling pathway. Dev. Biol. 244: 342-357.

Chuang, Y.Y., Valster, A., Coniglio, S.J., Backer, J.M., and Symons, M. 2007. The atypical Rho family GTPase Wrch-1 regulates focal adhesion formation and cell migration. J. Cell Sci. 120: 1927-1934.

Cowan, C.R. and Hyman, A.A. 2007. Acto-myosin reorganization and PAR polarity in C. elegans. Development 134: 1035-1043.

Dejmek, J., Safholm, A., Kamp Nielsen, C., Andersson, T., and Leandersson, K. 2006. Wnt-5a/Ca ${ }^{2+}$-induced NFAT activity is counteracted by Wnt-5a/Yes-Cdc42-casein kinase $1 \alpha$ signaling in human mammary epithelial cells. Mol. Cell. Biol. 26: 6024-6036.

Djiane, A., Riou, J., Umbhauer, M., Boucaut, J., and Shi, D. 2000. Role of frizzled 7 in the regulation of convergent extension movements during gastrulation in Xenopus laevis. Development 127: 3091-3100.

Eaton, S., Auvinen, P., Luo, L., Jan, Y.N., and Simons, K. 1995. CDC42 and Rac1 control different actin-dependent processes in the Drosophila wing disc epithelium. J. Cell Biol. 131: $151-164$.

Eaton, S., Wepf, R., and Simons, K. 1996. Roles for Racl and Cdc42 in planar polarization and hair outgrowth in the wing of Drosophila. J. Cell Biol. 135: 1277-1289. 
Endo, Y., Wolf, V., Muraiso, K., Kamijo, K., Soon, L., Uren, A., Barshishat-Kupper, M., and Rubin, J.S. 2005. Wnt-3a-dependent cell motility involves RhoA activation and is specifically regulated by dishevelled-2. J. Biol. Chem. 280: 777-786.

Esufali, S. and Bapat, B. 2004. Cross-talk between Rac1 GTPase and dysregulated Wnt signaling pathway leads to cellular redistribution of $\beta$-catenin and TCF/LEF-mediated transcriptional activation. Oncogene 23: 8260-8271.

Etienne-Manneville, S. and Hall, A. 2001. Integrin-mediated activation of Cdc42 controls cell polarity in migrating astrocytes through PKCzeta. Cell 106: 489-498.

Etienne-Manneville, S. and Hall, A. 2003. Cdc42 regulates GSK$3 \beta$ and adenomatous polyposis coli to control cell polarity. Nature 421: 753-756.

Etienne-Manneville, S., Manneville, J.B., Nicholls, S., Ferenczi, M.A., and Hall, A. 2005. Cdc42 and Par6-PKC $\zeta$ regulate the spatially localized association of Dlg1 and APC to control cell polarization. J. Cell Biol. 170: 895-901.

Fanto, M., Weber, U., Strutt, D.I., and Mlodzik, M. 2000. Nuclear signaling by Rac and Rho GTPases is required in the establishment of epithelial planar polarity in the Drosophila eye. Curr. Biol. 10: 979-988.

Gong, Y., Mo, C., and Fraser, S.E. 2004. Planar cell polarity signalling controls cell division orientation during zebrafish gastrulation. Nature 430: 689-693.

Goto, T. and Keller, R. 2002. The planar cell polarity gene strabismus regulates convergence and extension and neural fold closure in Xenopus. Dev. Biol. 247: 165-181.

Gotta, M., Abraham, M.C., and Ahringer, J. 2001. CDC-42 controls early cell polarity and spindle orientation in $C$. elegans. Curr. Biol. 11: 482-488.

Green, J.L., Inoue, T., and Sternberg, P.W. 2008a. Opposing Wnt pathways orient cell polarity during organogenesis. Cell 134: 646-656.

Green, J.L., Kuntz, S.G., and Sternberg, P.W. 2008b. Ror receptor tyrosine kinases: Orphans no more. Trends Cell Biol. 18: 536-544.

Grigoryan, T., Wend, P., Klaus, A., and Birchmeier, W. 2008. Deciphering the function of canonical Wnt signals in development and disease: Conditional loss- and gain-of-function mutations of $\beta$-catenin in mice. Genes \& Dev. 22: 2308-2341.

Habas, R., Kato, Y., and He, X. 2001. Wnt/Frizzled activation of Rho regulates vertebrate gastrulation and requires a novel Formin homology protein Daam1. Cell 107: 843-854.

Habas, R., Dawid, I.B., and He, X. 2003. Coactivation of Rac and Rho by Wnt/Frizzled signaling is required for vertebrate gastrulation. Genes \& Dev. 17: 295-309.

Hakeda-Suzuki, S., Ng, J., Tzu, J., Dietzl, G., Sun, Y., Harms, M., Nardine, T., Luo, L., and Dickson, B.J. 2002. Rac function and regulation during Drosophila development. Nature 416: 438442.

Hardin, J. and King, R.S. 2008. The long and the short of Wnt signaling in C. elegans. Curr. Opin. Genet. Dev. 18: 362-367.

Hardy, K.M., Garriock, R.J., Yatskievych, T.A., D'Agostino, S.L., Antin, P.B., and Krieg, P.A. 2008. Non-canonical Wnt signaling through Wnt5a/b and a novel Wnt1l gene, Wnt1lb, regulates cell migration during avian gastrulation. Dev. Biol. 320: 391-401.

Hawkins, N.C., Ellis, G.C., Bowerman, B., and Garriga, G. 2005. MOM-5 frizzled regulates the distribution of DSH-2 to control C. elegans asymmetric neuroblast divisions. Dev. Biol. 284: 246-259.

Henderson, B.R. and Fagotto, F. 2002. The ins and outs of APC and $\beta$-catenin nuclear transport. EMBO Rep. 3: 834-839.

Huang, H. and He, X. 2008. Wnt/B-catenin signaling: New (and old) players and new insights. Curr. Opin. Cell Biol. 20: 119-125.
Jaffe, A.B. and Hall, A. 2005. Rho GTPases: Biochemistry and biology. Annu. Rev. Cell Dev. Biol. 21: 247-269.

Jones, W.M. and Bejsovec, A. 2005. RacGap50C negatively regulates wingless pathway activity during Drosophila embryonic development. Genetics 169: 2075-2086.

Kawashima, T., Bao, Y.C., Nomura, Y., Moon, Y., Tonozuka, Y., Minoshima, Y., Hatori, T., Tsuchiya, A., Kiyono, M., Nosaka, T., et al. 2006. Racl and a GTPase-activating protein, $\mathrm{MgcRacGAP}$, are required for nuclear translocation of STAT transcription factors. J. Cell Biol. 175: 937-946.

Keller, R. 2002. Shaping the vertebrate body plan by polarized embryonic cell movements. Science 298: 1950-1954.

Kerr, B.A., Otani, T., Koyama, E., Freeman, T.A., and EnomotoIwamoto, M. 2008. Small GTPase protein Rac-1 is activated with maturation and regulates cell morphology and function in chondrocytes. Exp. Cell Res. 314: 1301-1312.

Kim, G.H. and Han, J.K. 2005. JNK and ROK function in the noncanonical Wnt/RhoA signaling pathway to regulate Xenopus convergent extension movements. Dev. Dyn. 232: 958 968.

Kinoshita, N., Sasai, N., Misaki, K., and Yonemura, S. 2008. Apical accumulation of rho in the neural plate is important for neural plate cell shape change and neural tube formation. Mol. Biol. Cell 19: 2289-2299.

Kishida, S., Yamamoto, H., and Kikuchi, A. 2004. Wnt-3a and Dvl induce neurite retraction by activating Rho-associated kinase. Mol. Cell. Biol. 24: 4487-4501.

Klein, T.J. and Mlodzik, M. 2005. Planar cell polarization: An emerging model points in the right direction. Annu. Rev. Cell Dev. Biol. 21: 155-176.

Kolsch, V., Seher, T., Fernandez-Ballester, G.J., Serrano, L., and Leptin, M. 2007. Control of Drosophila gastrulation by apical localization of adherens junctions and RhoGEF2. Science 315: 384-386.

Kuhl, M., Sheldahl, L.C., Park, M., Miller, J.R., and Moon, R.T. 2000. The Wnt $/ \mathrm{Ca}^{2+}$ pathway: A new vertebrate Wnt signaling pathway takes shape. Trends Genet. 16: 279-283.

Liu, W., Sato, A., Khadka, D., Bharti, R., Diaz, H., Runnels, L.W., and Habas, R. 2008. Mechanism of activation of the Formin protein Daam1. Proc. Natl. Acad. Sci. 105: 210-215.

Logan, C.Y. and Nusse, R. 2004. The Wnt signaling pathway in development and disease. Annu. Rev. Cell Dev. Biol. 20: 781810.

Malliri, A., Rygiel, T.P., van der Kammen, R.A., Song, J.Y., Engers, R., Hurlstone, A.F., Clevers, H., and Collard, J.G. 2006. The rac activator Tiam 1 is a Wnt-responsive gene that modifies intestinal tumor development. J. Biol. Chem. 281: 543-548.

Marlow, F., Topczewski, J., Sepich, D., and Solnica-Krezel, L. 2002. Zebrafish Rho kinase 2 acts downstream of Wnt11 to mediate cell polarity and effective convergence and extension movements. Curr. Biol. 12: 876-884.

Matsui, T., Raya, A., Kawakami, Y., Callol-Massot, C., Capdevila, J., Rodriguez-Esteban, C., and Izpisua Belmonte, J.C. 2005. Noncanonical Wnt signaling regulates midline convergence of organ primordia during zebrafish development. Genes \& Dev. 19: 164-175.

Matthews, H.K., Marchant, L., Carmona-Fontaine, C., Kuriyama, S., Larrain, J., Holt, M.R., Parsons, M., and Mayor, R. 2008. Directional migration of neural crest cells in vivo is regulated by Syndecan-4/Rac1 and non-canonical Wnt signaling/RhoA. Development 135: 1771-1780.

Miyakoshi, A., Ueno, N., and Kinoshita, N. 2004. Rho guanine nucleotide exchange factor XNET1 implicated in gastrulation movements during Xenopus development. Differentiation 72: $48-55$. 
Moeller, H., Jenny, A., Schaeffer, H.J., Schwarz-Romond, T., Mlodzik, M., Hammerschmidt, M., and Birchmeier, W. 2006. Diversin regulates heart formation and gastrulation movements in development. Proc. Natl. Acad. Sci. 103: 15900-15905.

Moriguchi, T., Kawachi, K., Kamakura, S., Masuyama, N., Yamanaka, H., Matsumoto, K., Kikuchi, A., and Nishida, E. 1999. Distinct domains of mouse dishevelled are responsible for the c-Jun $\mathrm{N}$-terminal kinase/stress-activated protein kinase activation and the axis formation in vertebrates. $J$. Biol. Chem. 274: 30957-30962.

Munoz-Descalzo, S., Gomez-Cabrero, A., Mlodzik, M., and Paricio, N. 2007. Analysis of the role of the Rac/Cdc42 GTPases during planar cell polarity generation in Drosophila. Int. J. Dev. Biol. 51: 379-387.

Nishita, M., Yoo, S.K., Nomachi, A., Kani, S., Sougawa, N., Ohta, Y., Takada, S., Kikuchi, A., and Minami, Y. 2006. Filopodia formation mediated by receptor tyrosine kinase Ror2 is required for Wnt5a-induced cell migration. J. Cell Biol. 175: 555-562.

Nobes, C.D. and Hall, A. 1999. Rho GTPases control polarity, protrusion, and adhesion during cell movement. J. Cell Biol. 144: 1235-1244.

Pan, W., Choi, S.C., Wang, H., Qin, Y., Volpicelli-Daley, L., Swan, L., Lucast, L., Khoo, C., Zhang, X., Li, L., et al. 2008. Wnt3amediated formation of phosphatidylinositol 4,5-bisphosphate regulates LRP6 phosphorylation. Science 321: 1350-1353.

Paricio, N., Feiguin, F., Boutros, M., Eaton, S., and Mlodzik, M. 1999. The Drosophila STE20-like kinase misshapen is required downstream of the Frizzled receptor in planar polarity signaling. EMBO J. 18: 4669-4678.

Penzo-Mendez, A., Umbhauer, M., Diiane, A., Boucaut, J.C., and Riou, J.F. 2003. Activation of G $\beta \gamma$ signaling downstream of Wnt-11/Xfz7 regulates Cdc42 activity during Xenopus gastrulation. Dev. Biol. 257: 302-314.

Phillips, H.M., Murdoch, J.N., Chaudhry, B., Copp, A.J., and Henderson, D.J. 2005. Vangl2 acts via RhoA signaling to regulate polarized cell movements during development of the proximal outflow tract. Circ. Res. 96: 292-299.

Polakis, P. 2007. The many ways of Wnt in cancer. Curr. Opin. Genet. Dev. 17: 45-51.

Purro, S.A., Ciani, L., Hoyos-Flight, M., Stamatakou, E., Siomou, E., and Salinas, P.C. 2008. Wnt regulates axon behavior through changes in microtubule growth directionality: A new role for adenomatous polyposis coli. J. Neurosci. 28: 8644-8654.

Qiang, Y.W., Walsh, K., Yao, L., Kedei, N., Blumberg, P.M., Rubin, J.S., Shaughnessy, J., and Rudikoff, S. 2005. Wnts induce migration and invasion of myeloma plasma cells. Blood 106: 1786-1793.

Rijsewijk, F., Schuermann, M., Wagenaar, E., Parren, P., Weigel, D., and Nusse, R. 1987. The Drosophila homolog of the mouse mammary oncogene int- 1 is identical to the segment polarity gene wingless. Cell 50: 649-657.

Rosso, S.B., Sussman, D., Wynshaw-Boris, A., and Salinas, P.C. 2005. Wnt signaling through Dishevelled, Rac and JNK regulates dendritic development. Nat. Neurosci. 8: 34-42.

Schlesinger, A., Shelton, C.A., Maloof, J.N., Meneghini, M., and Bowerman, B. 1999. Wnt pathway components orient a mitotic spindle in the early Caenorhabditis elegans embryo without requiring gene transcription in the responding cell. Genes \& Dev. 13: 2028-2038.

Schlessinger, K., McManus, E.J., and Hall, A. 2007. Cdc42 and noncanonical Wnt signal transduction pathways cooperate to promote cell polarity. J. Cell Biol. 178: 355-361.

Schmidt, A. and Hall, A. 2002. Guanine nucleotide exchange factors for Rho GTPases: Turning on the switch. Genes \& Dev. 16: 1587-1609.
Schwamborn, J.C. and Puschel, A.W. 2004. The sequential activity of the GTPases Rap1B and Cdc42 determines neuronal polarity. Nat. Neurosci. 7: 923-929.

Seifert, J.R. and Mlodzik, M. 2007. Frizzled/PCP signalling: A conserved mechanism regulating cell polarity and directed motility. Nat. Rev. Genet. 8: 126-138.

Shi, S.H., Jan, L.Y., and Jan, Y.N. 2003. Hippocampal neuronal polarity specified by spatially localized mPar3/mPar6 and PI 3-kinase activity. Cell 112: 63-75.

Shi, S.H., Cheng, T., Jan, L.Y., and Jan, Y.N. 2004. APC and GSK$3 \beta$ are involved in mPar3 targeting to the nascent axon and establishment of neuronal polarity. Curr. Biol. 14: 2025-2032.

Strutt, D.I. 2002. The asymmetric subcellular localisation of components of the planar polarity pathway. Semin. Cell Dev. Biol. 13: 225-231.

Strutt, D.I., Weber, U., and Mlodzik, M. 1997. The role of RhoA in tissue polarity and Frizzled signalling. Nature 387: 292-295.

Tahinci, E. and Symes, K. 2003. Distinct functions of Rho and Rac are required for convergent extension during Xenopus gastrulation. Dev. Biol. 259: 318-335.

Tanegashima, K., Zhao, H., and Dawid, I.B. 2008. WGEF activates Rho in the Wnt-PCP pathway and controls convergent extension in Xenopus gastrulation. EMBO J. 27: 606-617.

Tao, W., Pennica, D., Xu, L., Kalejta, R.F., and Levine, A.J. 2001. Wrch-1, a novel member of the Rho gene family that is regulated by Wnt-1. Genes \& Dev. 15: 1796-1807.

Ulrich, F., Krieg, M., Schotz, E.M., Link, V., Castanon, I., Schnabel, V., Taubenberger, A., Mueller, D., Puech, P.H., and Heisenberg, C.P. 2005. Wnt11 functions in gastrulation by controlling cell cohesion through Rab5c and E-cadherin. Dev. Cell 9: 555-564.

Upadhyay, G., Goessling, W., North, T.E., Xavier, R., Zon, L.I., and Yajnik, V. 2008. Molecular association between $\beta$-catenin degradation complex and Rac guanine exchange factor DOCK 4 is essential for $\mathrm{Wnt} / \beta$-catenin signaling. Oncogene 27: $5845-5855$.

Veeman, M.T., Axelrod, J.D., and Moon, R.T. 2003. A second canon. Functions and mechanisms of $\beta$-catenin-independent Wnt signaling. Dev. Cell 5: 367-377.

Wallingford, J.B., Rowning, B.A., Vogeli, K.M., Rothbacher, U., Fraser, S.E., and Harland, R.M. 2000. Dishevelled controls cell polarity during Xenopus gastrulation. Nature 405: 81-85.

Walston, T., Tuskey, C., Edgar, L., Hawkins, N., Ellis, G., Bowerman, B., Wood, W., and Hardin, J. 2004. Multiple Wnt signaling pathways converge to orient the mitotic spindle in early C. elegans embryos. Dev. Cell 7: 831-841.

Weber, U., Pataki, C., Mihaly, J., and Mlodzik, M. 2008. Combinatorial signaling by the Frizzled/PCP and Egfr pathways during planar cell polarity establishment in the Drosophila eye. Dev. Biol. 316: 110-123.

Weernink, P.A., Meletiadis, K., Hommeltenberg, S., Hinz, M., Ishihara, H., Schmidt, M., and Jakobs, K.H. 2004. Activation of type I phosphatidylinositol 4-phosphate 5-kinase isoforms by the Rho GTPases, RhoA, Rac1, and Cdc42. J. Biol. Chem. 279: 7840-7849.

Wei, Y.J., Sun, H.Q., Yamamoto, M., Wlodarski, P., Kunii, K., Martinez, M., Barylko, B., Albanesi, J.P., and Yin, H.L. 2002. Type II phosphatidylinositol 4-kinase $\beta$ is a cytosolic and peripheral membrane protein that is recruited to the plasma membrane and activated by Rac-GTP. J. Biol. Chem. 277: 46586-46593.

Winklbauer, R., Medina, A., Swain, R.K., and Steinbeisser, H. 2001. Frizzled-7 signalling controls tissue separation during Xenopus gastrulation. Nature 413: 856-860.

Winter, C.G., Wang, B., Ballew, A., Royou, A., Karess, R., Axelrod, J.D., and Luo, L. 2001. Drosophila Rho-associated 
kinase (Drok) links Frizzled-mediated planar cell polarity signaling to the actin cytoskeleton. Cell 105: 81-91.

Witze, E.S., Litman, E.S., Argast, G.M., Moon, R.T., and Ahn, N.G. 2008. Wnt5a control of cell polarity and directional movement by polarized redistribution of adhesion receptors. Science 320: 365-369.

Wu, M. and Herman, M.A. 2006. A novel noncanonical Wnt pathway is involved in the regulation of the asymmetric B cell division in C. elegans. Dev. Biol. 293: 316-329.

Wu, X., Tu, X., Joeng, K.S., Hilton, M.J., Williams, D.A., and Long, F. 2008. Rac1 activation controls nuclear localization of $\beta$ catenin during canonical Wnt signaling. Cell 133: 340-353.

Yang, S.A., Carpenter, C.L., and Abrams, C.S. 2004. Rho and Rho-kinase mediate thrombin-induced phosphatidylinositol 4-phosphate 5-kinase trafficking in platelets. J. Biol. Chem. 279: 42331-42336.

Yao, R., Natsume, Y., and Noda, T. 2004. MAGI-3 is involved in the regulation of the JNK signaling pathway as a scaffold protein for frizzled and Ltap. Oncogene 23: 6023-6030.

Yue, Q., Wagstaff, L., Yang, X., Weijer, C., and Munsterberg, A. 2008. Wnt3a-mediated chemorepulsion controls movement patterns of cardiac progenitors and requires RhoA function. Development 135: 1029-1037.

Zhang, X., Zhu, J., Yang, G.Y., Wang, Q.J., Qian, L., Chen, Y.M., Chen, F., Tao, Y., Hu, H.S., Wang, T., et al. 2007. Dishevelled promotes axon differentiation by regulating atypical protein kinase C. Nat. Cell Biol. 9: 743-754.

Zhu, S., Liu, L., Korzh, V., Gong, Z., and Low, B.C. 2006. RhoA acts downstream of Wnt5 and Wnt11 to regulate convergence and extension movements by involving effectors Rho kinase and Diaphanous: Use of zebrafish as an in vivo model for GTPase signaling. Cell. Signal. 18: 359-372. 


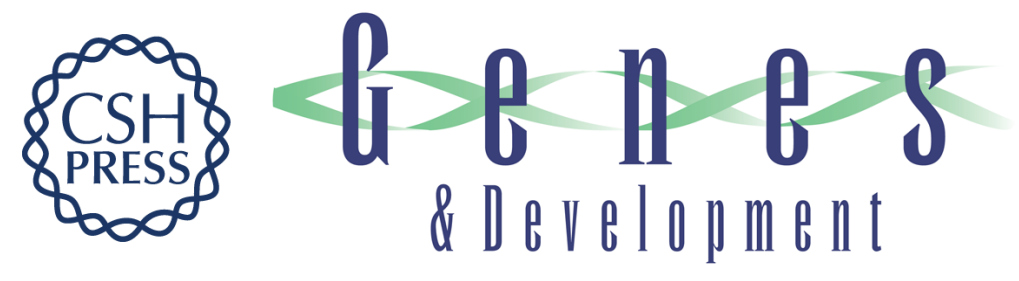

\section{Wnt signaling pathways meet Rho GTPases}

Karni Schlessinger, Alan Hall and Nicholas Tolwinski

Genes Dev. 2009, 23:

Access the most recent version at doi:10.1101/gad.1760809

References This article cites 95 articles, 40 of which can be accessed free at: http://genesdev.cshlp.org/content/23/3/265.full.html\#ref-list-1

License

Email Alerting Receive free email alerts when new articles cite this article - sign up in the box at the top Service right corner of the article or click here.

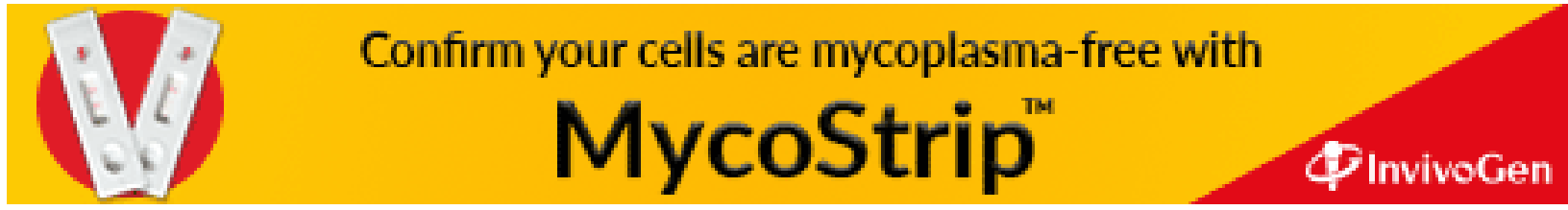

